\title{
Overcoming challenges in BIM and gaming integration: the case of a hospital project
}

\author{
A. Figueres-Munoz \& C. Merschbrock \\ Department of Civil Engineering and Energy Technology, \\ Oslo and Akershus University College, Norway
}

\begin{abstract}
Building Information Modeling (BIM) is a valuable technology for design in the architecture, engineering and construction (AEC) industry. Creating BIM-based computer games is a new application area of BIM technology that can provide an additional dimension to its utility by allowing facility users and designers to 'visit' the facility before it is completed. Scholars report that BIM games can be used in various areas such as construction site safety, building operation and design. Besides, games can aid in communicating architectural concepts to people not familiar with building construction. In this article, the integration of BIM and gaming is explored by analysing some of the issues emerging when integrating these technologies. A case study of a Norwegian construction project where a BIM model served as a graphical environment to develop a staff training game has been conducted. The findings are constructed by applying a relatively fresh theoretical approach, namely: Alter's Theory of Workarounds. The article explicates how practitioners cope with BIM-gaming integration challenges. Moreover, the consequences of their actions are elaborated. We find that existing approaches for resolving interoperability challenges are not properly applied in practice. Finally, we suggest key factors to improve BIM-gaming integration.

Keywords: BIM, gaming, integration, serious games, workarounds.
\end{abstract}

\section{Introduction}

Digital serious games have become a major trend in the global education market [1]. Serious games are used with educational purposes in several contexts. Ratan and Ritterfeld [2] report applications in academic education, military, and health, among others. An example of the latter is the use of videogames to train healthcare 
staff [3].The educational use of digital games has been a research topic for more than forty years [4]. In that time, serious games have proved their value for increasing learning [5].

Digital games have only recently emerged as an area within Architecture, Engineering and Construction (AEC) research. Accordingly, this technology is rarely applied in today's construction projects. To signify this, the Journal of Information Technology in Construction recently ran a special issue on the topic area [6]. It covered the use of digital games for academic education [7], building design optimization [8] and staff training [4].

This current interest in gaming is fuelled by the increasing availability of digital building design models. Building Information Modelling (BIM) systems are used as platforms of IT tools employed to design virtual models seeking to present all physical and functional characteristics of a building [9]. Not only does BIM drive innovation in the industry, it yields also potential for combinatorial innovation by combining it with other systems $[10,11]$. BIM's integration with gaming technology is an example of such combinatorial innovation. Here, BIM models are used as 3D graphical environments in 'serious games'.

On the technological side, BIM and gaming technologies use object-oriented programming (OOP) making the combination feasible [12, 13]. However, BIM has a legacy of integration issues, and there are challenges to combining these technologies [13-15]. These challenges are due to different data structures and ways to store information within each technology. Distorted geometries, missing textures or faults related to the overall organization of the model hierarchy are examples of frequently reported interoperability issues [13-18]. Thus BIM data is not always correctly interpreted by game engines. A game engine can be defined as the software used to produce and display images in real-time on the display device of a computer game [8]. Interoperability issues have been reported as an important reason for why integration of BIM and gaming is a challenging arena $[16,17]$.

Promising early stage results for converting BIM- to gaming-data have been achieved by developing dedicated software to undertake the "translation" [13, 16]. However, these systems are not yet commercially available and practitioners address the lack of interoperability by resorting to workarounds, as taking intermediary steps via other existing design systems to facilitate their file exchange [13]. An example of this would be to transform a Revit ${ }^{\circledR}$ file into a $3 \mathrm{DS}^{\circledR}$ file before importing it into Unity3 $\mathrm{D}^{\circledR}$

This article sets out to give an initial understanding of the 'messy' practice to overcome the lack of interoperability in BIM and gaming integration. To do so we ask the following research question in our inquiry:

How is BIM and gaming integration handled in practice and how can this integration be improved?

To answer the question, we ran a case-study in a Norwegian hospital construction project where BIM models of the new, yet unbuilt hospital served as a base for developing a video game. The project was the first application of a BIMbased game for professional training in a healthcare construction project in Norway. Our analysis is guided by Alter's 'Theory of Workarounds' [19]. 
Applying this theory enabled us to uncovering some of the issues emerging in BIM and gaming integration.

The structure of the article is as follows. First, we present Alter's 'Theory of Workarounds' [19]. Second, we present the hospital case. Third, we present the findings of our analysis based on the 'theory of workarounds'. Finally, we discuss the findings and provide practical suggestions of how to address BIM and gaming integration.

\section{Theoretical lens}

The article explores the practical work undertaken by construction professionals in their efforts to integrate BIM and gaming. Working based on BIM technologies is often messy and requires practitioners to resort to workarounds reconfiguring their work routines [14]. The theory of workarounds has been proposed as a novel analytical approach enabling the study of digital, messy, and practical work [19]. Workarounds are defined by Alter as 'goal-driven adaptation, improvisation, or other change to one or more aspects of an existing work system in order to overcome, bypass, or minimize the impact of obstacles, exceptions, anomalies, mishaps, established practices, management expectations, or structural constraints that are perceived as preventing that work system or its participants from achieving a desired level of efficiency, effectiveness, or organizational or personal goals' [19]. The concept of a work system in this context entails a 'system in which human participants and/or machines perform processes and activities using information, technology, and other resources to produce products/services for internal/external customers' [20].

The aforementioned theory has been deemed appropriate for our study since the emerging practices in BIM and gaming integration can be viewed as workarounds. The theory can be viewed as a process theory developed for 'classifying workarounds, analysing how they occur, for understanding compliance and noncompliance to methods and management mandates, for incorporating consideration of possible workarounds' [19].

The theory has its origins in loose coupling theory in which work is conceptualized along five voices [21]. Alter defines in his own five voices to classify workarounds. These are: (1) phenomena associated with workarounds; (2) types of workarounds; (3) direct effects of workarounds; (4) perspectives on workarounds; and (5) organizational challenges and dilemmas related to workarounds [19]. The interplay between these workaround voices is depicted in figure 1.

A staged research approach has been suggested for inquiries theoretically informed by workaround theory. A workaround study should identify: (1) intentions, goals, interests of each work participant; (2) structure, architecture and characteristics of the work system; (3) perceived need for workaround; (4) identification of workarounds by consideration of all knowledge available; (5) selection of workaround; (6) development and execution of the workaround; (7) local and broader consequences including advantages and disadvantages of the 


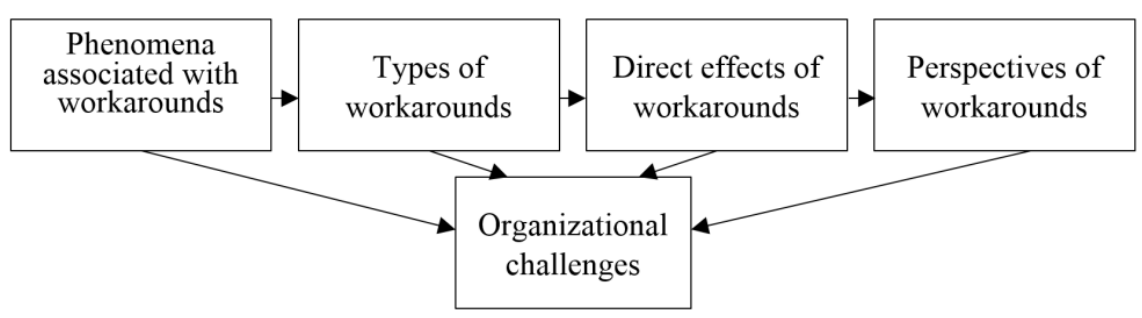

Figure 1: The five voices of workarounds (adapted [19]).

workaround. Workarounds can occur as 'quick-fixes' or improvisations lasting but a few seconds as well as routinized workflows lasting years. It has been suggested that workarounds may evolve from ad-hoc practices into systematized methods.

\section{Method}

A case study approach was chosen to explore BIM and gaming integration. A case study allows for exploring 'sticky, practice based problems where the experiences of the actors are important and the context of the action is critical' [22]. Moreover, it helps researchers in studying innovations put in place by practitioners [22]. Therefore, we considered this an appropriate strategy to answer the research question: 'How is BIM and gaming integration handled in practice and how can this integration be improved?' We explore a healthcare construction project in Østfold, Norway. The project comprises the construction of several facilities including buildings for the hospital itself and for services as laundry or central sterilization. The use of BIM technology in the design phase was defined as a strategic goal by the client in order to explore how to optimize facilities' operation by using available digital models. The client is the South-Eastern Norway Regional Health Authority (Helse Sør-Øst). A county hospital agency, Østfold Sykehus, will operate the facilities. The project's gross floor area is 85,082 square meters, and the cost estimate is $€ 670$ million. Prior to starting up the operation of the hospital, roughly 2500 staff will complete a training program to become familiar with the new work environment. Following the goal of optimizing facilities' operation, part of the training consists in playing the BIM based computer game. An alpha version of the game was developed to explore the possibilities of such a tool in the training, and to help the hospital management decide to what extent the game should be developed further. Afterwards, a full version consisting of three modules of the game targeting different staff groups was developed.

This setting was found to fit the purpose of our article: (1) BIM and gaming technologies were integrated to develop the staff-training programs, and (2) the game had reached a stage near completion.

Data collection was carried out from April 2013 to May 2014. Nine semistructured interviews and one focus group interview were conducted, involving altogether twelve individuals. Interviewees had either hands-on or managerial tasks in developing or testing the serious game. Representatives of each 
stakeholder group involved in the making of the game were interviewed. These groups were: (1) the clients' managers responsible for both the BIM model and the development of the game, (2) representatives of the four firms involved in developing the game's alpha- and full-versions, and (3) a range of healthcare professionals. Interviews details can be found in Table 1.

Table 1: Interviews conducted.

\begin{tabular}{|l|l|l|}
\hline Affiliation & Services provided & Date \\
\hline Client \#1 (regional health authority) & $\begin{array}{l}\text { Responsible BIM } \\
\text { manager (architecture, } \\
\text { engineering and } \\
\text { construction expert) }\end{array}$ & $\begin{array}{l}\text { April } 2013 \text { and } \\
\text { March 2014 }\end{array}$ \\
\hline Client \#2 (hospital) & $\begin{array}{l}\text { Responsible gaming } \\
\text { manager }\end{array}$ & March 2014 \\
\hline Developer \#1 (alpha version, Firm \#1) & 3D artist in game design & March 2014 \\
\hline Developer \#2 (alpha version, Firm \#2) & CEO and game developer & March 2014 \\
\hline Developer \#3 (alpha version, Firm \#3) & CEO and game developer & March 2014 \\
\hline Developer \#4 (full version, Firm \#4) & CEO & $\begin{array}{l}\text { March and } \\
\text { April 2014 }\end{array}$ \\
\hline Healthcare professional \#1 & $\begin{array}{l}\text { Counsellor game design, } \\
\text { experienced expert }\end{array}$ & May 2014 \\
\hline Healthcare professional \#2, \#3, \#4, \#5, \#6 & $\begin{array}{l}\text { Game testers, } \\
\text { experienced expert }\end{array}$ & May 2014 \\
\hline
\end{tabular}

Interviews were conducted face-to-face and in two instances via Skype. Interviews lasted on average forty minutes. All interviewees were informed about the modalities of the interviews and gave their informed consent for the process. The interviews were recorded, transcribed, and coded according to the concepts relevant in the theory of workarounds.

In addition to interviews, complementary data about the project was gathered from a game testing session and document analysis, e.g. trade press articles or public announcements.

\section{Analysis}

In what follows, BIM and gaming integration is analysed for the alpha and the full versions of the game. First, the workarounds practitioners resorted to are identified and presented, guided by the steps provided in the workaround theory. Second, these workarounds are classified according to the five voices of workarounds.

\subsection{The alpha version- BIM and gaming digital integration}

The county hospital agency to operate the facilities intended to explore the possibilities of using gaming technology for staff-training purposes. The hospital's intention was, put into words, to 'get a computer game as simple as possible for those not familiar with computer games' (Developer \#3). 
To that effect, they contracted three start-up companies anonymized here as Firm \#1, Firm \#2 and Firm \#3, all connected to a local business incubator. The goal of all three companies was to collaborate according to their strengths to efficiently create the computer game. Firms \#1 and \#2 would in the first place build a Unity3D(C) model (see Figure 2) to be used as scenario, and make it interactive, i.e. allow objects to respond the actions or commands. An example of that is to enable doors to be open and close. Then, Firm \#3 would develop the computer game's plot on the Unity model provided by Firms \#1 and \#2.

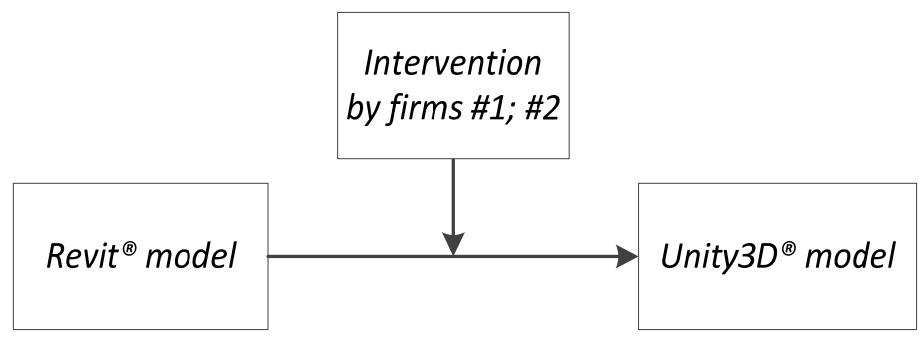

Figure 2: Interventions for BIM to game integration.

The perceived need for a workaround arose when Firm 1 tried to directly import the BIM model handed out by architects into the game engine. It was a $200 \mathrm{MB}$ file and according to Developer \#1, 'it appeared an importing size limit there. It just did not work (...). There was too much information, a game engine just needs what is visible, not everything lying inside the walls'. Developers missed a clear dialog with architects to ask for a simpler one matching their needs. Having access to a simpler BIM model of the facilities would have eased the integration with game engines. As Developer \#1 puts it: 'Architects can easily select surfaces, ceilings, interior claddings. And then just ignore the rest. Then save the model just with this information, so we would get a much less extensive one. This one model could be easily set into the game engine'.

The initial selection of the workaround to pursue was a consequence of the first attempt at importing the whole BIM model into the game engine and involved Firms \#1 and \#2. The workaround procedure consisted in (1) dividing the RevitC model in smaller models, (2) removing all unnecessary information, (3) importing these smaller models into Unity(C) and finally (4) addressing manually faults in textures and materials assigned to objects. The following quote illustrates how tedious the last step was: 'When they (Firm \#2) put this model in (the game engine), it followed all materials and textures. Something as simple as a window had three or four materials. So they had to go through it and (check the assigned materials). Very time consuming. It was too tiresome (...).Most of the work was about cleansing the model' (Developer \#1).

This workaround enabled the digital integration of BIM and gaming technologies. A broader consequence of this workaround, was reported by Developer \#3: 'the scene (resulting of importing the BIM model) was a big one, whereas in gaming we prefer having scenes in a one room scale. After going from 
a room to another room, these are dynamically created and removed to save computing resources'. Thus, using BIM models as a background for a computer game requires a more powerful computer to manage the graphics.

\subsection{The full version: BIM and gaming manual integration}

Based on the learning from the alpha version, the hospital decided to commission a new company, referred here to as Firm \#4, with the development of the full version of the game. This Firm counts with 20 years of experience in staff training and game development. According to its CEO, Developer \#4, 'Østfold Hospital wanted (us to do) a simulation of the workplaces to train staff (...) with a starting point in the BIM model and architect drawings, (...) implementing the best existing background information'. The firm's intention was, still according to its CEO, 'not to optimize the game (development), but create reflexion in the user' (Developer \#4).

The work system deployed this time had at its core a team of specialists within gaming and healthcare. This team was set by the hospital as a link and main contact between architects and game developers. The reason for establishing this link team can be explained by the following quote of its leader, Client \#2 describing his job: 'I communicate the hospitals needs to those developing the game, and vice versa, I am like a bridge in between, arguing and arranging meetings to make this as smooth as possible'. The setup seemed to engage Firm \#4 in this collaborative approach, as Developer \#4 considers 'We both (the client and Firm \#4) knew this was something we made together, but they have a project leader who is always available, that is essential to work this out'.

A first contact with the BIM model made Developer \#4 aware of the challenges of integrating BIM and gaming. This first contact was described as 'bad, really bad (...). The problem is that the BIM model is built in a completely different way and with a completely different starting point than what a game engine needs'. Furthermore, he pointed two main differences between BIM models and the required input of a game engine: (1) the required level of detail in the geometry of the environment, and (2) the modularity of the elements contained in them: '(when developing a game) you make just one window, (...) this window is then copied thousand times, but is still the same one. The computer understands that'. These differences were perceived as obstacles hindering digital integration. The perceived need for a workaround was made explicit in the following quote: 'you could never upload the whole hospital (to the game engine). It would never work'.

Only one potential workaround was identified, and thus selected. This consisted in developing the game geometrical background manually, not importing BIM data at all. As Developer \#4 puts it: 'the BIM model became then just a kind of 3D draft for us, and we build it (the game) up from scratch'.

This workaround was a means of integrating BIM and gaming data allowing practitioners to keep using established and well known work processes, yet it required re-entering of geometry and materials information manually. Modelling the geometrical background manually implied also that the game engine manages to render only surrounding 3D geometry when moving around in the game, not compromising computing resources. 


\subsection{Classification based on the five voices}

A classification of the two identified workarounds can be found in Table 2. Alter's five voice classification [19] permitted the identification of phenomena associated with each workaround, as well as their type, direct effects and perspectives. The fifth voice in the theory, the organizational challenges related to workarounds, accounts for the combination of the other four.

Table 2: Classification of workarounds according to Alter's [19] five voices.

\begin{tabular}{|c|c|c|c|c|}
\hline Workarounds & $\begin{array}{l}\text { Phenomena } \\
\text { associated with } \\
\text { workaround }\end{array}$ & $\begin{array}{c}\text { Types of } \\
\text { workaround }\end{array}$ & $\begin{array}{l}\text { Direct effects of } \\
\text { workaround }\end{array}$ & $\begin{array}{l}\text { Perspectives } \\
\text { of } \\
\text { workaround }\end{array}$ \\
\hline $\begin{array}{l}\text { Digital } \\
\text { integration } \\
\text { (alpha } \\
\text { version) }\end{array}$ & $\begin{array}{l}\text { Technology misfits } \\
\text { Obstacles inherent } \\
\text { in emergent process } \\
\text { Improvisation } \\
\text { Agency }\end{array}$ & \multirow{2}{*}{$\begin{array}{c}\text { Overcome } \\
\text { inadequate IT } \\
\text { functionality } \\
\text { Substitute for } \\
\text { unavailable } \\
\text { or inadequate } \\
\text { resources }\end{array}$} & $\begin{array}{l}\text { Continuation of } \\
\text { work } \\
\text { Creation of } \\
\text { inefficiencies } \\
\text { Impact on } \\
\text { subsequent } \\
\text { activities }\end{array}$ & $\begin{array}{l}\text { Creative act } \\
\text { Future } \\
\text { improvement }\end{array}$ \\
\hline $\begin{array}{l}\text { Manual } \\
\text { integration } \\
\text { (full version) }\end{array}$ & $\begin{array}{l}\text { Technology misfits } \\
\text { Obstacles inherent } \\
\text { in emergent process } \\
\text { Agency }\end{array}$ & & $\begin{array}{l}\text { Continuation of } \\
\text { work } \\
\text { Create } \\
\text { inefficiencies }\end{array}$ & Resistance \\
\hline
\end{tabular}

The two workarounds presented have many common features as they occurred in similar contexts. Both can be associated with obstacles inherent to innovative use of technology. Interoperability issues when trying to integrate BIM and gaming technologies can be seen as a technology misfit. This misfit was addressed differently in each workaround according to the firms' goals and desires, what can be considered an agency issue as suggested by Eisenhardt [23]. The workaround executed by firms \#1 and \#2 to integrate BIM and gaming showed a certain degree of improvisation, as these designed and executed the workaround at once.

More common features appear when defining what type of workarounds the presented ones were. Both of them can be classified as an overall way to compensate for an inadequate IT functionality, causing interoperability issues when integrating BIM and gaming. Furthermore, they can be seen as a way to substitute for unavailable or inadequate resources. However, slight differences should be pointed out here. Game developers from Firms \#1 and \#2 explicitly claimed the unavailability of sufficiently simplified BIM models, while game developer in Firm \#4 perceived these models were completely inadequate.

The most important direct effect of both workarounds is that they enabled practitioners to continue their work. Other identified direct effects of the two presented workarounds include the creation of inefficiencies as both entailed tedious and time consuming processes to integrate BIM and gaming technologies. 
In addition, the workaround related to the alpha version had an impact on the game development as a big scene required more computing power.

The studied workarounds offer different perspectives. On the one hand, digitally integrating BIM and gaming technologies regardless of the technological hurdles can be argued as a creative act, opening up for further improvements. Reflecting on how to face integration in the future, Developer \#1 was prompted to think of an improved workaround. The following quote shows his suggestion: 'I would first have opened the (BIM) model in a 3D graphics program, looked at it, and then take some kind of decision about what is easier (...). It will take a long time anyway. You have to find how to do it effectively. But do not take it into the game engine before you have cleansed everything, systematized materials, removed as much information as possible'. On the other hand, undertaking integration by manually modelling the geometrical background from scratch can be seen as a form of disengagement with the opportunities of an emerging, innovative practice.

The main challenge BIM-gaming integration offers is apparent, as the lack of interoperability had be addressed by resorting to workarounds. The dilemma of the organizations was either to undertake integration digitally, or manually.

\section{Discussion}

We have shown how practitioners resorted to workarounds to overcome challenges BIM-gaming integration poses. In what follows, we discuss why digital integration is preferable guided by Alter's five voices and elaborate key factors to improve digital BIM-gaming integration.

The reason practitioners should resort to workarounds to integrate BIM and gaming technologies was their perception of the technology currently aiding this innovation as constraining. They responded then with inertia and reinvention, avoiding a digital integration of BIM data and gaming technology and keeping using their work methods (inertia) or overcoming constraints by using technology in unintended ways as uploading a too heavy file into the game engine (reinvention). This finding is in line with former research by Boudreau and Robey [24].

Practitioners were aware of the technological challenges they faced when having to integrate BIM and gaming. They perceived an inadequate functionality of technology. Having an earlier involvement in the construction design phase, can make this perception different as practitioners could explore how to efficiently approach integration, allowing them to communicate their need properly. Thus, we propose that an earlier and more active involvement of game developers in the construction design phase is factor to improve digital BIM-gaming integration.

Both manually and digital integration enabled their original goal, integrate BIM and gaming technologies. However, these approaches required tedious and timeconsuming processes to success. Literature shows different workflows to efficiently export BIM data into game engines $[15,17,18]$. These include several software tools and multiple steps. Kumar et al. [17] found importing BIM data directly into the game engine through a FBX file format to be the best workflow 
when aiming to transfer as much information as possible. Recent research recommends taking an intermediate step by importing BIM data to Autodesk 3DS Max $\mathbb{C}$, and then to the game engine $[15,18]$ to overcome the reported inaccuracies related to distorted geometries, missing textures and the overall organization of the model hierarchy [13-18]. This proposed workflow can be seen as a routinized workaround as several researchers have tested and reported improvements to the process, and illustrates that a digital BIM-gaming integration is affordable. However, the lack of knowledge of up to date research made all practitioners in the case study undergo a 'painful' process. Those who digitally integrated BIM and gaming came to a similar proposal just after improvising a more demanding workaround, and those who undertook the manually integration never glimpsed the effort-saving opportunities digital integration offers. Thus, we suggest that another key factor to improve digital BIM-gaming integration is to establish a mutual information between research and practice.

The digital integration of BIM and gaming technologies has proven its suitability to evolve into a systematized method and gain from software development. The last key factor to improve digital BIM-gaming integration is then encouraging to use BIM technology during facilities operation phase, as this would drive further required developments.

\subsection{Contributions}

This article contributes to research by providing an initial understanding of how practitioners handled with a digital innovation in the construction industry, namely, BIM and gaming integration. Provided that only one case study has been analysed, further research is needed to validate our findings and provide an exhaustive account on this topic. Moreover, we argue that Alter's theory of workaround useful to explore the messy practices around BIM-gaming integration. This study contributes to practice as well. We have reported weaknesses of current attempts to integrate BIM and gaming technologies, and suggested factors to improve the practical integration. The AEC industry can gain from the learning drawn from other professionals' experiences and our conclusions.

\section{Conclusion}

This article aimed to cast some light to the messy practices to overcome challenges in BIM and gaming integration. We have presented current approaches to BIMgaming integration and the consequences these entailed. Moreover we have suggested how this integration could be improved. Technology aiding BIMgaming integration was perceived as constraining, and practitioners resorted to workarounds to enable the use of BIM data as geometrical background for computer games. Current approaches to do so consisted in either (1) digitally integrate BIM and gaming regardless of the technological hurdles, or (2) in manually re-entering information from the BIM model into gaming software. Although both approaches entailed tedious and time-consuming processes, only the digital integration resembles proposed workflows to efficiently integrate BIM 
and gaming, and opened for further improvements. Key factors to improve BIM and gaming digital integration are: (1) early and active involvement of game developers in the design phase, (2) establishment of a mutual information between research and practice, and (3) encouragement of the use of BIM during facilities operation phase.

\section{References}

[1] Susi, T., Johannesson, M. \& Backlund, P., Serious Games: An Overview, IKI Technical Reports, School of Humanities and Informatics, University of Skövde: Sweden, 2007.

[2] Ratan, R. \& Ritterfeld, U., Classifying Serious Games (Chapter 2). Serious Games: Mechanisms and Effects, ed. U. Ritterfeld, M. Cody, P. Vorderer, Routledge: New York, pp. 10-24, 2009.

[3] Merschbrock, C., Lassen, A.-K. \& Tollnes, T., Integrating BIM and Gaming to Support Building Operation: The Case of a New Hospital. Proc. of Norsk konferanse for organisasjoners bruk av IT, 22(1), pp. 1-13, 2014.

[4] Lin, K.-Y., Son J.W. \& Rojas, E.M., A Pilot Study of a 3D Game Environment for Construction Safety Education. Journal of Information Technology in Construction, 16(5), pp. 69-83, 2011.

[5] Wong, W.L., Shen, C., Nocera, L., Carriazo, E., Tang, F., Bugga S., Narayanan, H., Wang \& H., Ritterfeld, U., Serious Video Game Effectiveness. Proc. of the International Conference on Advances in Computer Entertainment Technology, ed ACM: New York, pp. 49-55, 2007.

[6] Raju, P., Anumba, C. \& Ahmed, V., Editorial-Use of Gaming Technology in Architecture, Engineering and Construction. Journal of Information Technology in Construction, 16(11), pp. 1-2, 2011.

[7] Juang, J.R., Hung, W.H. \& Kang, S.C., Using Game Engines for Physicalbased Simulations - a Forklift. Journal of Information Technology in Construction, 16(2), pp. 3-22, 2011.

[8] Shiratuddin, M.F. \& Thabet, W., Utilizing a 3D Game Engine to Develop a Virtual Design Review System. Journal of Information Technology in Construction, 16(4), pp. 39-68, 2011.

[9] United States National Building Information Modelling Standard; National Institute of Building Science, Online, 2007.

[10] Boland Jr, R.J., Lyytinen, K. \& Yoo, Y., Wakes of Innovation in Project Networks: The Case of Digital 3-D Representations in Architecture, Engineering, and Construction. Organization Science, 18(4), pp. 631-647, 2007.

[11] Varian, H.R., Computer Mediated Transactions. The American Economic Review, 16, pp. 1-10, 2010.

[12] Pokkunuri, B.P., Object Oriented Programming. ACM Sigplan Notices, 24(11), pp. 96-101, 1989. 
[13] Yan, W., Culp, C. \& Graf, R., Integrating BIM and Gaming for Real-time Interactive Architectural Visualization. Automation in Construction, 20(4), pp. 446-458, 2011.

[14] Dossick, C.S. \& Neff, G., Constructing Teams: Adapting Practices and Routines for Collaboration through BIM. Proc. of the Engineering Project Organization Conference, eds. P. Carrillo \& P. Chinoswky, Engineering Project Organizations Conference (EPOS): Denver, 2013.

[15] Dalton, B. \& Parfitt, M., Immersive Visualization of Building Information Models. Design Innovation Research Center Working Paper 6 [1.0], Design Innovation Research Centre, University of Reading: Reading, 2013.

[16] Shen, Z., L., Grosskopf, K. \& Berryman, C., Creating 3D Web-based Game Environment Using BIM Models for Virtual On-site Visiting of Building HVAC Systems. Proc. of the Construction Research Congress, ed H. Cai, A. Kandil, M. Hastak \& P. S. Dunston, American Society of Civil Engineers: West Lafayette, pp. 1212-1221, 2012.

[17] Kumar, S., Hedrick, M., Wiacek, C. \& Messner, JI., Developing an Experienced-based Design Review Application for Healthcare Facilities Using a 3D Game Engine. Journal of Information Technology in Construction, 16(6), pp. 3-22, 2011.

[18] Computer Integrated Construction Research Group. Workflow of Exporting Revit Models to Unity, Penn State CIC Research Group, 2014.

[19] Alter, S., Theory of Workarounds. Communications of the Association for Information Systems, 34(55), pp. 1041-1066, 2014.

[20] Alter, S., Work System Theory: Overview of Core Concepts, Extensions, and Challenges for the Future. Journal of the Association for Information Systems, 14(2), pp. 72-121, 2013.

[21] Orton, J.D. \& Weick, K.E., Loosely Coupled Systems: A Reconceptualization. Academy of Management Review, 15(2), pp. 203-223 1990.

[22] Benbasat, I., Goldstein, D.K. \& Mead, M., The Case Research Strategy in Studies of Information Systems. MIS quarterly, 11(3), pp. 369-386, 1987.

[23] Eisenhardt, K.M., Agency Theory: An Assessment and Review. Academy of Management Review, 14(1), pp. 57-74, 1989.

[24] Boudreau, M.-C. \& Robey, D., Enacting Integrated Information Technology: A Human Agency Perspective. Organization Science, 16(1), pp. 3-18, 2005. 